Sedimentary environments

Sedimentary Environments and Facies. Edited by H. G. Reading. Pp. 557. (Blackwell Scientific: Oxford, UK, 1978.) Hardback £22.50; paperback $£ 13$.

THIS book describes modern sedimentary environments and their ancient analogues. For each major facies the editor has arranged for a chapter to be written by an internationally recognised authority on that particular topic. The book commences with an introductory chapter and a chapter on facies by the editor. These are followed by chapters on alluvial, lacustrine and desert deposits by Collinson. Elliott continues with chapters on deltas and clastic shorelines, and these are followed by a chapter by Till on arid shorelines and evaporites. Johnson has contributed a chapter on shallow siliclastic seas (sic) and this is followed by one from Sellwood on shallow-water carbonates.

Moving into deeper water Jenkyns and Rupke cover pelagic environments and deep clastic seas respectively. Edwards concludes the spectrum of environments with a contribution on glacial deposits. For a finale Reading and Mitchell have written a chapter relating facies to plate tectonics and the book closes with an epilogue from the editor, a bibliography and a subject index.

As the preceding resumé shows, this work is a veritable tour de force. It is well researched, well written and comprehensive, both in the range of environments described and in the global coverage of supporting case-histories. The illustrations all appear to have been redrawn from their original sources so that the book has a pleasing uniform appearance (though this review copy had several grey pages due to an apparent shortage of printers ink).

The emphasis of most of the authors is on the relationship between sedimentary processes and the macroscopic features of their deposits. Thus, the major theme of the book is concerned with the study of lithological sequences and their contained sedimentary structures and fossils.

The emphasis is on macrofacies rather than microfacies. It would have been interesting to have had contributions from this distinguished team of authors on the relationship between sedimentary processes, and the texture and petrophysics of their deposits. This would have widened the appeal of the book for many industrial geologists concerned with the relationship between facies, porosity and permeability. This absence of attention to microfacies is particularly apparent in the sections on carbonates, which contain not a single microphotograph.

Similarly it would have been useful to read how the authors see facies analysis in relation to other branches of geology. One of the most stimulating chapters is the one which shows how facies relate to tectonics. It would be interesting to know more about the relationship of facies to stratigraphy (both conventional and seismic), to microfacies and petrophysics (as already mentioned), and to the ways in which facies analysis is applied in the exploration for coal, oil, gas, water and sedimentary ores. This deficiency is particularly apparent when subsurface case-histories are described. It is not sufficiently stressed that these have been interpreted largely from microfacies and wireline logs, as cores are

\section{Meteorite reference work}

The Nature and Origin of Meteorites. By D. W. Sears. Pp. 187. (Adam Hilger: Bristol, UK, 1978.) £13.50.

THIS is an excellent reference work on meteorites, being comprehensive in scope, yet succinct. The book is divided into six chapters. The first is a historical introduction which makes interesting reading and helps put the succeeding chapters in their proper context. I was glad that "the tortuous and sometimes confusing route by which modern classification schemes have emerged" was dealt with briefly. This is a useful chapter because it indicates how closely advances in physics, chemistry and the Earth sciences have been bound to meteorite research; and this is still true.

Chapter 2 deals with atmospheric flight and impact phenomena, including tektites, which are probably proproduced in rare, high energy events by fusion or vaporisation of terrestrial materials. Various casehistories of meteorite falls are given. Statistics indicate that, over the Earth as a whole, two or three meteorites arrive per day, yet samples from only about six observed falls per year actually reach the scientist. Next comes 'Classification, mineralogy and petrology'. Here the author, in my opinion rightly, concentrates on the major groups of meteorites, key references to the others being given. The scope of the chapter is, however, wider than the title implies, for estimates of the sizes of meteorite parent-bodies are included. The fourth chapter is on chemical composition and covers the observational data and their theoretical modelling and interpretation. In view of the seldom available for the detailed study of their macroscopic features. Only two figures in the book show the use of wireline logs in subsurface facies analysis. No doubt space was the reason why these topics were omitted, and indeed the editor is to be congratulated on the way so much valuable material has been compressed into 550 pages.

There is no doubt that this scholarly book will be invaluable as a text for senior undergraduate and postgraduate students aiming for an academic career. It will also be an essential source book for all geologists concerned with sedimentary rocks.

R. C. Selley

R. C. Selley is Reader in Petroleum Geology at Imperial College, University of London, $U K$.

sometimes bitter antagonism among those engaged in the field, Sears has done well to present the different cases lucidly, with fair indication of their strengths and pit-falls. Then comes 'Physical properties and processes', including age and isotopic studies. Unfortunately there is no reference to the samarium-neodymium results which have recently made a strong impact on our understanding of the history of terrestrial rocks.

The last chapter is a synthesis of our ideas on the age and origin of meteorites. Because of its extreme brevity, uninitiated readers will have to refer to the preceding text, but most of the necessary cross-references are there.

The book is well produced and contains few errors; on p121 the seismic velocity in sandstone is given as 3,000 to $4,000 \mathrm{~km}$ per second (it should be $\mathrm{m}$ per second), and I am sure that I would enjoy studying a 'cosmogenic tract' (p148). Table 4.1, on meteorite compositions, contains numerous errors and is useless for reference. Both author and publisher are to be congratulated in producing the book so quickly that references up to early 1978 are included, but I wish that titles had not been omitted.

From the points of view of price, accuracy and being up to date, I can recommend this as a good reference text. However, in spite of the statement on the dust-cover, it will be beyond the comprehension of most amateur astronomers and geologists, and is probably more advanced than is necessary for undergraduates. It will be most useful for research students and academics; they will be unable to do better for the price.

Robert Hutchison

R. Hutchison is a Principal Scientific Officer in the Mineralogy Department of the British Museum (Natural History). 